\title{
AVALIAÇÃO DE UM PROGRAMA DE FORMAÇÃO EM HABILIDADES SOCIAIS DOCENTES NA PERSPECTIVA DE PROFESSORES E ALUNOS
}

\author{
EVALUACIÓN DE UN PROGRAMA DE CAPACITACIÓN EN HABILIDADES \\ SOCIALES PARA PROFESORES DESDE LA PERSPECTIVA DE PROFESORES Y \\ ESTUDIANTES
}

\section{EVALUATION OF A SOCIAL SKILLS FORMATION PROGRAM FOR TEACHERS FROM THE PERSPECTIVE OF TEACHERS AND STUDENTS}

\author{
José Angelo FIOROT JUNIOR ${ }^{1}$ \\ Maria Lucia Oliveira Suzigan DRAGONE ${ }^{2}$
}

RESUMO: O objetivo desta pesquisa, de cunho qualitativo e quantitativo, é a avaliação de um Programa de Formação em Habilidades Sociais Docentes - PFHS-D, pela perspectiva dos professores e de seus alunos do Ensino Médio. A pesquisa se justifica pela necessidade de conduzir estudos sobre formação de professores, voltados para a interação afetiva com alunos adolescentes da educação básica, carente de intervenções e desafiada continuamente pelas políticas públicas que conduzem a uma precarização do trabalho docente. Como método para avaliar o PFHS-D utilizou-se testes específicos e questionários obtendo dados com docentes e alunos, buscando sinais de melhora ou piora nas interações e nas Habilidades Sociais dos professores. Participaram desta pesquisa 5 professores e 13 alunos de uma escola do noroeste do Estado de São Paulo. Os resultados apontaram que houve aquisição significativa de novos comportamentos socialmente hábeis, confirmados tanto pelas avaliações conduzidas com os professores quanto com seus alunos.

PALAVRAS-CHAVE: Habilidades sociais docentes. Formação continuada. Avaliação.

RESUMEN: El objetivo de esta investigación, de cuño cualitativo y cuantitativo, es la evaluación de un Programa de Capacitación en Habilidades Sociales para Maestros (PFHSD), desde la perspectiva de los maestros y sus estudiantes (de la escuela secundaria). La investigación se justifica por la necesidad de realizar estudios sobre la formación del profesorado, dirigidos a la interacción afectiva com estudiantes adolescentes em educación básica, com uma falta de intervenciones y continuamente cuestionados por políticas públicas que conducen a uma precariedade del trabajo docente. Como método para evaluar el PFHS$D$, se utilizaron pruebas y cuestionarios especificos, obteniendo datos de maestros y estudiantes, buscando signos de mejora o empeoramiento en las interacciones y en las habilidades sociales de los maestros. Cinco maestros y 13 estudiantes de una escuela en el noroeste del estado de São Paulo participaron en esta investigación. Los resultados mostraron que hubo una adquisición significativa de nuevos comportamientos socialmente

\footnotetext{
${ }^{1}$ Universidade de Araraquara (UNIARA), Araraquara - SP - Brasil. Mestrado em Processos de Ensino, Gestão e Inovação. ORCID: https://orcid.org/0000-0001-7646-3077.E-mail: joseangelo@me.com

${ }^{2}$ Universidade de Araraquara (UNIARA), Araraquara - SP - Brasil. Docente no Programa de Pós-graduação em Processos de Ensino Gestão e Inovação. Doutorado em Educação Escolar (UNESP). Apoio Funadesp. ORCID: https//orcid.org/000-0002-4567-0679. E-mail: mldragone@uniara.com.br
} 
calificados, confirmados tanto por las evaluaciones realizadas con los maestros como con sus alumnos.

PALABRAS CLAVE: Enseñanza de habilidades sociales. Educación continua. Evaluación.

ABSTRACT: The objective of this research, of qualitative and quantitative nature, is the evaluation of a Social Skills Formation Program for Teachers - PFHS-D (Portuguese initials), from the perspective of teachers and their high school students. The research is justified by the need to conduct studies on teacher education, focused on affective interaction with basic education adolescent students, which is lacking in interventions and continually challenged by public policies that lead to a precariousness of teaching work. As a method to evaluate the PFHS-D, specific tests and questionnaires were used, obtaining data from teachers and students, looking for signs of improvement or worsening in the interactions and in the Social Skills of teachers. Five teachers and 13 students from a school in the northwest of the State of São Paulo participated in this research. The results showed that there was a significant acquisition of new socially skilled behaviors, confirmed both by assessments conducted with teachers and their students.

KEYWORDS: Teacher social skills. Continuing formation. Evaluation.

\section{Introdução}

A abordagem do tema Habilidades Sociais Docentes pressupõe um entendimento acerca do comportamento e das interações humanas decorrentes. Estudos conduzidos na área (DEL PRETTE; DEL PRETTE, 1997; 2011; 2013; 2018; CABALLO, 1999; BOLSONISILVA, 2002; MANOLIO, 2009; GRESHAM, 2013; HENRIQUE, 2017) sinalizam que o comportamento humano ocorre por meio das diversas interações entre os organismos e o meio desde o nascimento, com modelagem, modelação e outros mecanismos de aprendizado, e que as habilidades não são desenvolvidas de forma igual para todos, indicando que uma mesma pessoa pode ter desenvolvido comportamentos bastante habilidosos, ao passo que também podem haver déficits de aquisição em outros aspectos comportamentais para situações específicas, o que pode ou não comprometer sua competência social. Essas habilidades e déficits são, em grande medida, adquiridos na socialização primária, junto da família, e ampliadas ao longo dos anos nas interações escolares. Essa temática foi estudada em pesquisa, ora relatada, desenvolvida em nível de mestrado pelo primeiro autor, envolvendo a estruturação de um programa específico de formação em habilidades sociais para professores e avaliação de seus efeitos. 


\section{Escola em transformação: o Ensino Médio e as demandas em Habilidades Sociais Docentes}

Dentre as diversas mudanças em curso na escola encontra-se uma convergência para os problemas advindos da democratização do espaço escolar (TEDESCO, 2001; FORMOSINHO, 2009). Essa democratização de acesso trouxe consigo alguns "problemas" que a escola não enfrentava antes da massificação. É a crise do exterior que vai para dentro da escola, intensificada pelo aumento do número de anos obrigatórios, tornando o espaço e a atividade docente mais complexa, heterogênea e diferenciada do ponto de vista da qualificação (FORMOSINHO, 2009).

A educação básica abarca, além do Ensino Fundamental, o Ensino Médio - etapa de ensino que é tratada neste trabalho e que é pouco investigada por pesquisadores. Além disso, também é uma etapa bastante frágil para a universalização do ensino em nosso país, uma vez que, a cada dez jovens com 19 anos no Brasil, quatro não concluem esta etapa (IBGE, 2018). $\mathrm{O}$ olhar mais atento para esta fase da educação focando questões relativas às habilidades sociais de professores pode contribuir para a melhoria de algumas condições presentes na sala de aula e que podem favorecer a permanência e o envolvimento destes alunos na própria escolarização.

Quando se pensa em Ensino Médio também deve-se considerar a alta penalização que seus professores sofrem pelas políticas públicas, pois vivenciam condições de trabalho desafiadoras, como a precarização e intensificação provocados por influências dos organismos internacionais destacando-se a produtividade e sistemas de avaliação em larga escala, o que pode tornar a educação nessa etapa bastante mecânica pela necessidade de cumprir metas, algo que pode impactar diretamente a afetividade e as relações entre docentes e alunos.

Constatando essa demanda junto à professores de uma escola no Noroeste do Estado de São Paulo, o primeiro autor deste artigo elaborou uma proposta de formação docente, denominada Programa de Formação em Habilidades Sociais Docentes - PFHS-D (FIOROT JR, 2020) com base nos trabalhos de Caballo (1999), propondo as seguintes etapas para a elaboração de um programa nesse sentido: avaliação de situação; experienciação de novas situações e comportamentos na prática; avaliação de comportamentos (ansiedade, conteúdo verbal e não verbal) e prática de novos comportamentos. Além destas etapas, incluiu-se no Programa de Formação a prática do follow up que, segundo o autor, é de fundamental importância para a verificação da eficácia da proposta. Neste trabalho, objetiva-se a avaliação, em diferentes momentos da pesquisa, dos dados coletados com os docentes e alunos para 
averiguar se sinalizavam uma melhora ou piora nas interações e, consequentemente, nas Habilidades Sociais dos professores.

\section{A Estrutura do Programa de Formação em Habilidades Sociais Docentes (PFHS-D)}

O PFHS-D foi estruturado com um agrupamento de procedimentos, dinâmicas e técnicas articuladas de forma a promover uma reformulação do modo desapropriado de expressão nas relações interpessoais a serem detectadas no grupo a ser trabalhado, como mostrado na Figura 1:

Figura 1 - Quadro do Programa de Formação em Habilidades Sociais Docentes - PFHS-D

\begin{tabular}{|c|c|c|c|c|}
\hline \multicolumn{2}{|r|}{ Encontro / Objetivos } & \multirow{2}{*}{$\begin{array}{l}\text { Conceitos principais } \\
\text { Habilidades Sociais; } \\
\text { Trabalho ético; } \\
\text { Inventário de } \\
\text { Habilidades Sociais } \\
\text { (IHS) (DEL PRETTE; } \\
\text { DEL PRETTE, 2018). }\end{array}$} & \multirow{2}{*}{$\begin{array}{l}\begin{array}{l}\text { Atividades } \\
\text { desenvolvidas }\end{array} \\
\text { - Respostas dos } \\
\text { professores ao Inventário } \\
\text { de Habilidades Sociais, } \\
\text { antes da formação. }\end{array}$} & \multirow{2}{*}{$\begin{array}{l}\text { Materiais } \\
\text { - Formulário do } \\
\text { IHS; } \\
\text { - Caneta; } \\
\text { - Caderno para } \\
\text { registros; } \\
\text { - Slides. } \\
\end{array}$} \\
\hline $\mathbf{1}^{\mathbf{0}}$ & $\begin{array}{l}\text { - Apresentar o PFHS-D } \\
\text { - Autoavaliação } \\
\text { docente acerca das } \\
\text { Habilidades Sociais } \\
\text { (IHS) }\end{array}$ & & & \\
\hline $2^{\circ}$ & $\begin{array}{l}\text { - Explorar a temática } \\
\text { do Fator } 1 \text { do IHS } \\
\text { (comunicação } \\
\text { assertiva) e exercitá-la. }\end{array}$ & $\begin{array}{l}\text { Comunicação Assertiva: } \\
\text { os tipos passivo, } \\
\text { assertivo e agressivo nas } \\
\text { interações (DEL } \\
\text { PRETTE; DEL } \\
\text { PRETTE, 2013); }\end{array}$ & $\begin{array}{l}\text { - Praticar respostas } \\
\text { assertivas (DEL PRETTE; } \\
\text { DEL PRETTE, 2017); } \\
\text { - Vivência: A fumaça e a } \\
\text { justiça (DEL PRETTE; } \\
\text { DEL PRETTE, 2017). }\end{array}$ & $\begin{array}{l}\text { - Folhas com } \\
\text { exercícios e textos; } \\
\text { - Caneta e cadernos } \\
\text { para registros; } \\
\text { - Slides }\end{array}$ \\
\hline $3^{\circ}$ & $\begin{array}{l}\text { - Explorar o Fator } 2 \text { do } \\
\text { IHS (abordagem } \\
\text { afetiva) e praticá-lo; } \\
\text { - Apresentar o conceito } \\
\text { de Tríplice } \\
\text { Contingência } \\
\text { (SKINNER, 2007). }\end{array}$ & $\begin{array}{l}\text { Abordagem afetiva. } \\
\text { Eventos antecedentes e } \\
\text { consequentes } \\
\text { (SKINNER, 2007). } \\
\text { Automonitoria. } \\
\text { Expressão de } \\
\text { sentimentos e afeto. }\end{array}$ & $\begin{array}{l}\text { - Leitura de um trecho do } \\
\text { livro Comunicação não } \\
\text { violenta (Rosenberg, } \\
\text { 2006, p.63-78); } \\
\text { - Jogo GROK (KING; } \\
\text { MORRISON, 2018). }\end{array}$ & $\begin{array}{l}\text { - Textos impressos; } \\
\text { - Caneta e cadernos } \\
\text { para registros; } \\
\text { - Cartas do Jogo } \\
\text { GROK. } \\
\text { - Slides. }\end{array}$ \\
\hline $4^{0}$ & $\begin{array}{l}\text { - Explorar o Fator } 3 \text { do } \\
\text { IHS (expressão de } \\
\text { sentimentos positivos); } \\
\text { - Exercitar o } \\
\text { oferecimento e a } \\
\text { recepção de feedbacks. }\end{array}$ & $\begin{array}{l}\text { Diferenciação entre } \\
\text { elogios e feedbacks; } \\
\text { Prática de feedbacks } \\
\text { assertivos. }\end{array}$ & $\begin{array}{l}\text { - Relatos de caso dos } \\
\text { próprios participantes } \\
\text { (interação com o grupo } \\
\text { para discussão da } \\
\text { assertividade, ou não, dos } \\
\text { feedbacks oferecidos } \\
\text { como exemplo). }\end{array}$ & $\begin{array}{l}\text { - Folhas com } \\
\text { exercícios e textos; } \\
\text { - Caneta e cadernos } \\
\text { para registros; } \\
\text { - Slides. }\end{array}$ \\
\hline $\mathbf{5}^{\circ}$ & $\begin{array}{l}\text { - Explorar o Fator } 4 \text { do } \\
\text { IHS (autocontrole e } \\
\text { enfrentamento) e } \\
\text { praticá-lo diante de } \\
\text { situações estressoras. } \\
\text { - Apresentar a cultura } \\
\text { da automonitoria. }\end{array}$ & $\begin{array}{l}\text { Autocontrole e } \\
\text { enfrentamento. }\end{array}$ & $\begin{array}{l}\text { - Relatos de casos dos } \\
\text { participantes; } \\
\text { - Vivência com perguntas } \\
\text { e respostas sobre } \\
\text { situações estressoras; } \\
\text { - Sugestões de } \\
\text { enfrentamento; } \\
\text { - Técnicas de } \\
\text { automonitoria. }\end{array}$ & $\begin{array}{l}\text { - Folhas com } \\
\text { exercícios e textos; } \\
\text { - Caneta e cadernos } \\
\text { para registros; } \\
\text { - Slides. } \\
\text { - Livro em cards } \\
\text { Coaching in a Box } \\
\text { (LIPPI, 2010). }\end{array}$ \\
\hline $6^{0}$ & $\begin{array}{l}\text { - Explorar o Fator } 5 \text { do } \\
\text { IHS (desenvoltura } \\
\text { social) e praticá-lo. }\end{array}$ & $\begin{array}{l}\text { Desenvoltura Social; } \\
\text { Elogios; } \\
\text { Questionamentos; }\end{array}$ & $\begin{array}{l}\text { - Vivência - "Vamos } \\
\text { conhecer Pedrinho" (DEL } \\
\text { PRETTE; DEL PRETTE, } \\
\text { 2017, p. 220). } \\
\text { - Práticas de } \\
\text { automonitoria. }\end{array}$ & $\begin{array}{l}\text { - Folhas com } \\
\text { exercícios e textos; } \\
\text { - Caneta e cadernos } \\
\text { para registros; } \\
\text { - Slides }\end{array}$ \\
\hline $7^{\circ}$ & $\begin{array}{l}\text { - Verificar a } \\
\text { autoavaliação docente } \\
\text { acerca das Habilidades } \\
\text { Sociais. } \\
\text { - Conduzir o } \\
\text { fechamento do PFHS- } \\
\text { D. }\end{array}$ & $\begin{array}{l}\text { Inventário de } \\
\text { Habilidades Sociais } \\
\text { (IHS); } \\
\text { Devolutiva dos } \\
\text { encontros. }\end{array}$ & $\begin{array}{l}\text { - Respostas dos } \\
\text { professores ao Inventário } \\
\text { de Habilidades Sociais, } \\
\text { após a formação. }\end{array}$ & $\begin{array}{l}\text { - Formulário do } \\
\text { IHS; } \\
\text { - Caneta; } \\
\text { - Caderno para } \\
\text { registros; } \\
\text { - Slides. }\end{array}$ \\
\hline
\end{tabular}

Fonte: Fiorot Jr (2020) 
Considerando que um Programa de Formação de Habilidades Sociais, segundo Del Prette e Del Prette (2017), tem caráter educativo ou preventivo, no sentido de corrigir comportamentos inadequados específicos ou instrumentalizar adicionalmente os sujeitos a atuar no meio de forma eficaz, a avaliação inicial dos participantes é essencial, pois, além de detectar as habilidades já praticadas pelos participantes, oferece orientação para um planejamento que busque reflexões sobre habilidades menos praticadas pelo grupo, o que pode garantir o seu sucesso ou fracasso, em termos de mudanças de comportamento do grupo de trabalho. Se voltarmos a nossa atenção para a escola, será possível perceber que a aplicação desta proposta encontra um terreno fértil para o seu desenvolvimento, pois a educação trata, essencialmente, de processos complexos de relacionamento e interação entre os sujeitos.

\section{Participantes da pesquisa}

Esta pesquisa, desenvolvida a nível de mestrado, com projeto aprovado por Conselho de Ética em pesquisa com Seres Humanos. Foi realizada numa escola de Ensino Médio do noroeste do Estado de São Paulo com a adesão de doze professores, dos quais foi possível contemplar os dados de apenas cinco (por falta em um dos encontros, conforme critérios de inclusão e exclusão previstos). Também participaram da pesquisa alunos do segundo ano do Ensino Médio, para os quais os professores participantes lecionavam. Dos 63 convidados, 13 alunos efetivamente participaram da pesquisa.

\section{Instrumentos de coleta de dados}

a) O Inventário de Habilidades Sociais - 2 (IHS - 2). Trata-se de um teste padronizado com edição publicada pela Editora Casa do Psicólogo - Pearson Clinical do Brasil (DEL PRETTE; DEL PRETTE, 2001), e com nova versão autorizada apenas à psicólogos (IHS-2) publicada em 2018. Possui uma escala de autoavaliação do tipo Likert de cinco pontos, distribuídos em duas extremidades: nunca ou raramente; sempre ou quase sempre. Os 38 itens presentes na escala devem ser respondidos pelos sujeitos com base em estimativas sobre a frequência com que se reage (ou se sente) frente às situações descritas em cada item.

A interpretação dos resultados é feita por meio de um escore geral, que evidencia a existência de recursos positivos ou déficits em habilidades sociais do sujeito, obtida por percentis a partir do Grupo Amostral de Referência (utilizado para padronização do 
instrumento) e de cinco fatores, representados como F1, F2, F3, F4 e F5 (DEL PRETTE; DEL PRETTE, 2018), que avaliam: - F1 (13 itens) - conversação assertiva (Habilidades de autoafirmação em situações de enfrentamento com risco potencial de reação indesejável por parte do interlocutor - possibilidade de réplica ou oposição); - F2 (3 itens) - abordagem afetiva (Habilidades de expressão afetiva, incluindo iniciar e manter conversação com pessoas recém-conhecidas); - F3 (8 itens) - expressão de sentimento positivo (habilidades para expressar e lidar com demandas de expressão de afeto positivo diante de familiares e outros); - F4 (5 itens) - autocontrole/enfrentamento (habilidades para lidar com situações que demandam autocontrole e enfrentamento com risco potencial de reação indesejável por parte do interlocutor); - F5 (6 itens) - desenvoltura social - trata-se de um conjunto de habilidades que expressam desinibição e "traquejo social" diante de demandas interativas em geral.

b) Questionário desenvolvido pelo pesquisador contendo quatro perguntas, sendo uma objetiva e fechada com respostas dadas em uma escala linear e outras três dissertativas, no qual os alunos avaliaram os professores que aceitaram participar do Programa de Formação.

A $1^{\text {a }}$ questão, objetiva e quantificável por Escala Visual Analógica (EVA), apresenta dez comportamentos para que os alunos avaliem a emissão destes por seus professores. A Escala Visual Analógica (EVA) é uma ferramenta útil para o pesquisador que precisa lidar com as medidas objetivas de fenômenos subjetivos, pois permite o tratamento estatístico dos dados, os quais, de outra forma, só seriam analisados qualitativamente (COX; DAVISON, 2005). A Escala Visual Analógica tem 100 mm (sem marcação de graduação), com limites à direita (a melhor condição esperada para o atributo) e à esquerda (a pior condição esperada pelo avaliador). Ao avaliador é pedido que marque uma linha vertical cruzando o local que descreva melhor, na sua percepção, o atributo observado. A distância da extremidade esquerda até o ponto no qual ocorrem as marcações dos avaliadores será medida em centímetros e milímetros, oferecendo o resultando em dados numéricos sobre o desempenho dos professores em cada atributo (MARTINEZ; GRASSI; MARQUES, 2011).

Os dez itens avaliados em Escala Visual Analógica estavam relacionados com os fatores avaliados pelo IHS-2 da seguinte maneira: - Item A - referente ao Fator 1 (comunicação assertiva); - Itens C e D - referentes ao Fator 2 (abordagens afetivas e declaração de sentimentos e necessidades); - Item H e J - referentes ao Fator 3 (enfocando expressão de sentimento positivo, prática de elogios e feedbacks); - Item B, E, F, G e I referentes ao Fator 4 (autocontrole e enfrentamento). O Fator 5 do IHS-2 (desenvoltura social) não foi incluído nesta questão. 
Havia, ainda, outras três questões abertas, que demandavam respostas escritas livres dos alunos, para os seguintes questionamentos: $2^{\mathrm{a}}$ questão - comportamentos do professor que facilitam o aprendizado da turma; $3^{\mathrm{a}}$ questão - o que mais lhe incomoda em seu professor e; $4^{\mathrm{a}}$ questão - definir, com uma palavra, o comportamento geral de seu professor. As três perguntas abertas pediam justificativas para cada resposta.

O IHS-2 foi apresentado e respondido pelos professores no primeiro e no último encontro, ou seja, antes e após a participação no PFHS-D. Já o questionário dos alunos foi apresentado e respondido antes da participação dos docentes no PFHS-D e em esquema de follow up, após dois meses do término desta.

A opção pela aplicação de um protocolo padronizado e um questionário com perguntas abertas e outras utilizando Escala Visual Analógica, deu-se em razão do preconizado por Minayo e Sanches (1993), quando afirmam que os dados quantitativos e qualitativos podem gerar questões que dialogam entre si, produzindo uma análise complementar na busca pela realidade observada durante o estudo, por exemplo.

\section{Análise dos dados dos professores}

Passa-se agora à exposição dos resultados da autoavaliação dos professores pelo IHS-2 antes e após o PFHS-D.

Figura 2 - Tabela de Percentis totais IHS antes e após a realização do PFHS-D

\begin{tabular}{c|c|c|c|c|c|c|c|c|c|c}
\hline \multirow{2}{*}{} & \multicolumn{2}{|c|}{ P1 } & \multicolumn{2}{c|}{ P2 } & \multicolumn{2}{c|}{ P3 } & \multicolumn{2}{c}{ P4 } & \multicolumn{2}{c}{ P5 } \\
\cline { 2 - 11 } & antes & depois & antes & depois & antes & depois & antes & depois & antes & depois \\
\hline Geral & 70 & $\mathbf{8 0}$ & 35 & $\mathbf{9 5}$ & 65 & $\mathbf{8 0}$ & 45 & 40 & 85 & 85 \\
\hline F1 & 45 & $\mathbf{5 0}$ & 25 & $\mathbf{7 5}$ & 50 & $\mathbf{5 0}$ & 35 & $\mathbf{3 5}$ & $\mathbf{7 0}$ & 45 \\
\hline F2 & 60 & $\mathbf{6 0}$ & 45 & $\mathbf{9 7}$ & 90 & $\mathbf{9 5}$ & 35 & $\mathbf{3 5}$ & 45 & 70 \\
\hline F3 & 90 & $\mathbf{1 0 0}$ & 45 & $\mathbf{7 5}$ & 25 & $\mathbf{4 5}$ & 45 & $\mathbf{2 0}$ & 60 & 65 \\
\hline F4 & 70 & $\mathbf{9 0}$ & 55 & $\mathbf{9 5}$ & 75 & $\mathbf{9 0}$ & 60 & $\mathbf{8 0}$ & 90 & 100 \\
\hline F5 & 65 & $\mathbf{8 0}$ & 25 & $\mathbf{8 0}$ & 75 & $\mathbf{9 0}$ & 35 & $\mathbf{8 0}$ & 55 & 85 \\
\hline
\end{tabular}

Legenda: -Branco: percentis melhoraram; cinza claro: percentis iguais; cinza escuro: percentis pioraram. -F1: comunicação assertiva; F2: abordagem afetiva; F3: expressão de sentimento positivo; F4: autocontrole e enfrentamento; F5: desenvoltura social.

Fonte: Fiorot Jr (2020) 
De forma geral, com a aplicação do IHS-2, foi possível verificar que os dados dos professores P1, P2 e P3 evidenciam um aumento de pontos em percentil no escore geral do teste, indicando ganhos significativos após a participação no PFHS-D.

Os professores P4 e P5 mantiveram seus escores inalterados ou sinalizaram piora, respectivamente, o que pode ser atribuído à possibilidade de terem adquirido mais consciência sobre os seus comportamentos passando a ser mais rigorosos em suas autoavaliações. Tais dados combinam com as considerações de Villas Boas, Silveira e Bolsoni-Silva (2005) sobre ser um trabalho com habilidades sociais um gatilho para o aumento de autocrítica e nível de exigência na avaliação dos comportamentos dos participantes, gerando dados com ligeira piora ou inalterações de valor.

Para Cozby (2003), ao se submeter a um pré-teste, pode ocorrer uma modificação do comportamento dos sujeitos da pesquisa, maximizando o seu desempenho. Ao mesmo tempo, também pode ocorrer o contrário, quando o instrumento de avaliação é aplicado mais de uma vez, como foi o caso desta pesquisa, tornando-o desgastado. Neste caso, o participante pode se cansar ou ainda mudar os padrões de resposta ao teste, o que pode ter acontecido com os docentes P4 e P5.

A melhora dos percentis do grupo em 16 pontos, entretanto, eleva o grupo, segundo o manual de apuração do IHS-2 de "bom repertório de habilidades sociais, com resultados dentro da média para a maior parte dos itens ou equilíbrio entre recursos e déficit nesses itens e subescalas em que aparecem" para o resultado atual de "repertório elaborado de habilidades sociais, com resultados acima da média para a maior parte dos itens e subescalas em que aparecem. Indicativo de recursos interpessoais bastante satisfatórias" (DEL PRETTE; DEL PRETTE, 2018, p. 75).

Sendo assim, o PFHS-D (FIOROT JR, 2020) proposto neste trabalho foi de relevância, pois trouxe ganhos efetivos da ordem de $70 \%$ para os professores, também com dados coincidentes para os alunos que avaliaram esses docentes, conforme dados apresentados no próximo item.

\section{Análise dos dados dos alunos}

A Figura 3 apresenta os valores médios aferidos a partir dos escores obtidos por marcações na Escala Visual Analógica sobre o comportamento de seus professores antes e após dois meses (esquema de follow up) da participação deles no PFHS-D. 
Figura 3 - Tabela de dados comparativos por fatores segundo percepção dos alunos e escores da Escala Virtual Analógica de 0 a 10 - antes e depois do PFHS-D

\begin{tabular}{c|c|c|c|c|c|c|c|c|c|c}
\hline & \multicolumn{2}{|c|}{ P1 } & \multicolumn{2}{c|}{ P2 } & \multicolumn{2}{c|}{ P3 } & \multicolumn{2}{c}{ P4 } & \multicolumn{2}{c}{ P5 } \\
\hline & antes & depois & antes & depois & antes & depois & antes & depois & antes & depois \\
\hline F1 & 9,27 & $\mathbf{9 , 4 3}$ & 9,7 & $\mathbf{9 , 8 5}$ & 8,78 & $\mathbf{9 , 3 6}$ & 8,04 & $\mathbf{9 , 3 8}$ & 8,9 & $\mathbf{8 , 1 3}$ \\
\hline F2 & 7,26 & $\mathbf{8 , 9}$ & 9,24 & $\mathbf{9 , 4 6}$ & 7,75 & $\mathbf{8 , 2 6}$ & 7,24 & $\mathbf{6 , 4 4}$ & 8,3 & $\mathbf{8 , 6}$ \\
\hline F3 & 8,51 & $\mathbf{8 , 4 3}$ & 8,99 & $\mathbf{9 , 1 9}$ & 8,49 & $\mathbf{9 , 1 1}$ & 7,04 & $\mathbf{5 , 7 6}$ & 8,43 & $\mathbf{9 , 0 2}$ \\
\hline F4 & 7,64 & $\mathbf{7 , 2 8}$ & 9,32 & $\mathbf{9 , 4 7}$ & 8,59 & $\mathbf{8 , 6 1}$ & 7,53 & $\mathbf{7 , 3 6}$ & 8,32 & $\mathbf{8 , 9 5}$ \\
\hline
\end{tabular}

Legenda:

-F1: comunicação assertiva; F2: abordagem afetiva; F3: expressão de sentimento positivo; F4: autocontrole e enfrentamento; F5: desenvoltura social.

-Cor branca (escores melhorados; Cor cinza (escores piorados).

Fonte: Fiorot Jr (2020)

Na percepção dos alunos, segundo os dados apresentados na Figura 3, quatorze valores demonstram melhora em habilidades sociais da ordem de 0,02 e 1,64 pontos na Escala Visual Analógica, e houve piora em seis deles, da ordem de 0,08 e 1,28 pontos. Em valores de porcentagem, os alunos perceberam mudanças positivas em $70 \%$ dos dados coletados e $30 \%$ sinalizaram mudanças negativas em habilidades sociais para os seus professores.

\section{Opiniões dos alunos antes e após o PFHS-D segundo análise das respostas no questionário}

Os dados referentes às respostas abertas dos alunos sobre as habilidades sociais presentes no comportamento de seus professores estão organizados de acordo com as respostas reincidentes entre todos os alunos, o que permitiu relacioná-las com cada um dos fatores elencados também no IHS-2.

A identificação de referências a Comunicação Assertiva (fator 1) foi feita por algumas expressões utilizadas pelos alunos, tais como: o professor dialoga, explica quantas vezes for necessário, usa palavras fáceis, utiliza exemplos, explica com detalhes. Notou-se relações com Abordagem Afetiva (fator 2) quando os alunos citaram expressões como: é carinhoso, é compreensivo ou é amoroso. Para as referências de Expressão de Sentimento Positivo (fator 3), os alunos utilizaram termos como: o professor elogia e está mais amigável. $\mathrm{O}$ fator 4, que relaciona habilidades de Autocontrole e Enfrentamento foram verificadas nas falas dos alunos com expressões como: é justo com quem não quer aprender, mantém mais a ordem, agora combina silêncio para não atrapalhar, consegue ser firme com quem não cumpre combinados. A Desenvoltura Social (fator 5), apareceu na fala dos alunos com expressões como: interage 
mais, é dinâmico e tem promovido mais debates e está muito mais animado na hora de explicar.

A partir das análises reincidentes das respostas dos alunos, os dados qualitativos permitiram quantificar a presença dos fatores antes e após a formação e houve sinalização de que os professores tiveram ganho em habilidades sociais e aparentemente passaram a praticar em sala de aula os conceitos e as práticas aprendidas durante o PFHS-D, conforme exposto na Figura 4:

Figura 4 - Tabela da percepção dos alunos sobre a presença de habilidades sociais dos professores

\begin{tabular}{l|c|c}
\hline Sobre presença dos Fatores IHS & Antes & Depois \\
\hline Fator 1 & 5 & 5 \\
Comunicação assertiva & P1-P2-P3-P4-P5 & P1-P2-P3-P4-P5 \\
\hline Fator 2 & 0 & P2-P3 \\
Abordagem afetiva & 0 & 3 \\
\hline Fator 3 & & P1-P2-P3 \\
Expressão de sentimento positivo & 0 & 3 \\
\hline $\begin{array}{l}\text { Fator 4 } \\
\text { Autocontrole e enfrentamento }\end{array}$ & 2 & P2-P3-P5 \\
\hline $\begin{array}{l}\text { Fator 5 } \\
\text { Desenvoltura Social }\end{array}$ & P2-P5 & 5 \\
\hline
\end{tabular}

Fonte: Fiorot Jr (2020)

No questionário, também foi solicitada a opinião dos alunos sobre os comportamentos de seus professores que lhes incomodavam, antes e depois da participação deles no PFHS-D. Esta sondagem tinha a intenção de obter dados preliminares para o trabalho com os professores durante a formação e, na análise pós-formação, foi positivo, pois tais dados poderiam reforçar por outro ângulo a avaliação de melhorias ou não de comportamentos negativos após os professores serem expostos aos diversos fatores de habilidades sociais no PFHS-D.

Sob esse prisma os alunos apontaram em suas respostas escritas comportamentos que consideravam como negativos para todos os professores, tais como: timidez, insegurança, passividade, dificuldade em controlar disciplina, atitudes mais brutas como soco na lousa para pedir silêncio, fala muito rápida ou alta com conteúdo confuso, falar demais (prolixo), braveza exagerada, ser estressado, broncas ou grosserias que diminuem o aluno.

Os resultados antes e depois da participação dos docentes no PFHS-D encontram-se na Figura 5: 
Figura 5 - Tabela da percepção dos alunos sobre aspectos negativos no comportamento dos professores

\begin{tabular}{l|c|c|c|c|c|c}
\hline ANTES DO PFHS-D P1 & P2 & P3 & P4 & P5 & total \\
\hline Timidez & $\mathrm{X}$ & & & & & 1 \\
\hline $\begin{array}{l}\text { Atitudes mais bruta (soco na } \\
\text { lousa, fala alta) para } \\
\text { controlar disciplina }\end{array}$ & & $\mathrm{X}$ & & $\mathrm{X}$ & $\mathrm{X}$ & 3 \\
\hline Fala excessiva ou alta & & $\mathrm{X}$ & $\mathrm{X}$ & $\mathrm{X}$ & & \\
\hline Confuso para explicar & & & $\mathrm{X}$ & & & 3 \\
\hline Estressado & & & & $\mathrm{X}$ & 1 \\
\hline $\begin{array}{l}\text { Broncas que diminuem os } \\
\text { alunos }\end{array}$ & & & & $\mathrm{X}$ & & 1 \\
\hline Fica bravo facilmente & & & & $\mathrm{X}$ & & 1 \\
\hline $\begin{array}{l}\text { Mudança de atitude de bravo } \\
\text { para passivo }\end{array}$ & & & & & $\mathrm{X}$ & 1 \\
\hline DEPOIS DO PFHS-D & melhorou & melhorou & melhorou & manteve & manteve & \\
\hline
\end{tabular}

Fonte: Fiorot Jr (2020)

Destaca-se que na percepção dos alunos nas respostas ao questionário, a comunicação assertiva estava presente nos cinco professores antes da participação no PFHS-D, embora em seguida tenham apontado os comportamentos de timidez ou outros comportamentos que os incomodavam. No entanto, desses casos, três dos professores parecem ter melhorado perante os alunos após o PFHS-D, pois houve indicação de mudança na comunicação assertiva, na expressão de sentimentos ou na desenvoltura social. Dois dos professores ainda permaneceram com comportamentos negativos, pois mantinham a mesma conduta, ainda que tentassem minimizá-los.

No Figura 6, a seguir, apresenta-se a compilação de todas as opiniões dos alunos e de seus professores sobre as habilidades sociais comparando-as antes e após o PFHS-D: 
Figura 6 - Quadro da comparação entre dados de autoavaliação docente e discentes

\begin{tabular}{|c|c|c|c|c|c|c|c|c|c|c|c|c|c|c|c|}
\hline & \multicolumn{3}{|c|}{ PROFESSOR 1 } & \multicolumn{3}{|c|}{ PROFESSOR 2 } & \multicolumn{3}{c|}{ PROFESSOR 3 } & \multicolumn{3}{c|}{ PROFESSOR 4 } & \multicolumn{3}{c|}{ PROFESSOR 5 } \\
\hline Fator & IHS & EVA & Q & IHS & EVA & Q & IHS & EVA & Q & IHS & EVA & Q & IHS & EVA & Q \\
\hline F1 & + & + & + & + & + & + & $=$ & + & + & - & - & + & $=$ & - & + \\
\hline F2 & + & + & -- & + & + & + & + & + & + & + & - & - & $=$ & + & - \\
\hline F3 & + & - & + & + & + & + & + & + & + & + & - & - & - & + & - \\
\hline F4 & + & - & -- & + & + & + & + & + & + & + & - & - & + & + & + \\
\hline F5 & + & $/ /$ & + & + & $/ /$ & + & + & $/ /$ & + & + & $/ /$ & + & + & $/ /$ & + \\
\hline
\end{tabular}

Legenda:

-F1: comunicação assertiva; F2: abordagem afetiva; F3: expressão de sentimento positivo; F4: autocontrole e enfrentamento; F5: desenvoltura social

-IHS: percepção de habilidades sociais/professores; EVA: escala virtual analógica/alunos; Q: questionário/alunos.

- (+) melhor (-) pior (=) igual; (//) item ausente na avaliação dos alunos; (--) aluno não respondeu.

-Cinza claro: aspectos concordantes entre as avaliações; Cinza escuro: aspectos discordantes; Branco: não analisado.

Fonte: Fiorot Jr (2020)

A Figura 6 foi construída a partir de todos os dados coletados nos instrumentos de pesquisa. Na comparação entre as avaliações dos alunos e a autoavaliação docente, há 25 possibilidades entre os dados linha a linha de cada fator. Em 14 dos dados, ou seja, para 56\% das possibilidades há concordância entre alunos e docentes sobre a melhora nas habilidades sociais após a participação no PFHS-D. O quadro também oferece uma reflexão sobre os instrumentos de pesquisa e sobre a estratégia do esquema de avaliação em follow up, proposto aos alunos, que coletou dados dos comportamentos dos professores dois meses após a formação, garantindo dados avaliativos longitudinais, embora em curto espaço de tempo. Mesmo assim a coleta indicou melhoria em Habilidades Sociais dos professores e concordaram em mais de 50\% com a autoavaliação feita pelos próprios docentes, confirmando os resultados positivos do PFHS-D.

\section{Considerações finais}

É necessário destacar que para a realização de um Programa como o proposto neste artigo é imprescindível a intervenção contínua ao longo de todo o processo, desde a avaliação inicial até a final. Os docentes devem ter contato com diversas práticas e recursos para que possam experimentar a forma adequada de se comportar que melhor se adapte à sua história de vida e seus recursos internos já instalados desde o nascimento, modelados pela família e 
sociedade em geral. Garantidas essas condições mínimas de aplicação do programa, as demais variáveis que podem afetar a proposta dizem respeito às pessoas e sua subjetividade. Isto permite a compreensão de resultados que, por vezes, ficam aquém do esperado nas hipóteses dos programas de formação em habilidades sociais. É preciso levar em consideração que cada indivíduo se comporta de acordo com a forma como adquiriu experiências ao longo de sua trajetória de vida, assim, modificar esses comportamentos pode ser custoso e difícil. Para isso, a Psicologia traz em benefício da educação (e quaisquer outras áreas de atuação do ser humano nas mais diversas realidades e contextos) uma série de técnicas e instrumentos que permitem avaliar, mobilizar recursos internos e, efetivamente, modificar comportamentos.

A partir de dados, oriundos das respostas dos professores e alunos nos protocolos utilizados, foi possível concluir que o programa proposto para este grupo foi positivo para os docentes que dele participaram, o que pode ter contribuído para a sua prática profissional os fazendo mobilizar novas ferramentas e formas de se comportar em prol de relações mais salutares com seus alunos (e nas demais situações interativas, já que as ferramentas ensinadas podem sofrer generalização para quaisquer situações da vida). A análise das opiniões dos alunos, tanto os dados quantitativos na escala linear como os qualitativos por respostas aos questionários, confirmaram que a participação de seus professores no PFHS-D contribuiu para o aprimoramento das relações em sala de aula.

A participação dos professores no Programa de Formação em Habilidades Sociais Docentes - PFHS-D (FIOROT JR, 2020), aparentemente, capacitou-os para atuar de forma mais assertiva, sabendo expressar seus sentimentos com sinceridade, ampliando a capacidade de se controlar e saber reagir quando em situações estressoras, e elevou o traquejo social nas mais variadas demandas e contendas da escola e das interações com os alunos, confirmando a hipótese inicial deste estudo.

Portanto, a realização de programas de formação em habilidades sociais, como o exposto e testado nesta pesquisa, pode contribuir com interações mais significativas entre alunos e professores e, ao melhorar esta interação, toda a comunidade escolar pode se beneficiar no processo de formação do Ensino Médio e, também, nas demais etapas da educação como um todo.

\section{REFERÊNCIAS}

BOLSONI-SILVA, A. T.; MARTURANO, E. M. Práticas educativas e problemas de comportamento: uma análise à luz das habilidades sociais. Estud. psicol., Natal, v. 7, n. 2, p. 227-235, jul. 2002. Disponível em: 
http://www.scielo.br/scielo.php?script=sci_arttext\&pid=S1413-

294X2002000200004\&lng=en\&nrm=iso. Acesso em: 15 abr. 2020.

CABALLO, V. E. Manual de técnicas de terapia e modificação do comportamento. São Paulo: Santos Editora, 1999.

COX, J.M.; DAVISON, A. The visual analogue scale as a tool for self-reporting of subjective phenomena in the medical radiation sciences. The Radiographer, Sydney, v. 1, n. 52, p. 2224. Disponível em:

http://www.minnisjournals.com.au/articles/rad\%20apr\%2005\%20visual\%20analogue $\% 20$ scal e.pdf. Acesso em: 9 abr. 2020.

DEL PRETTE, A.; DEL PRETTE, Z. A. P. Habilidades sociais e construção de conhecimento em contexto escolar. In: ZAMIGNANI, D. F. (Org.). Sobre comportamento e cognição. Santo André: ARBytes Editora, 1997. v. 3, cap. 2, p. 234-250.

DEL PRETTE, A.; DEL PRETTE, Z. A. P. Habilidades sociais e educação: pesquisa e atuação em psicologia escolar / educacional. In: DEL PRETTE, Z. A. P. (Org.) Psicologia escolar e educacional, saúde e qualidade de vida. 4. ed. Campinas. Alínea, 2011. cap. 6, p. 109-137.

DEL PRETTE, A.; DEL PRETTE, Z. A. P. Psicologia das relações interpessoais: vivências para o trabalho em grupo. 2. ed. Petrópolis: Editora Vozes, 2013.

DEL PRETTE, A.; DEL PRETTE, Z. A. P. Competência social e habilidades sociais: manual teórico prático. Petrópolis: Vozes, 2018.

DEL PRETTE, A.; DEL PRETTE, Z. A. P. Inventário de Habilidades Sociais -2 (IHS-2 Del-Prette): manual de aplicação, apuração e interpretação. São Paulo: Pearson Clinical Brasil, 2018.

DEL PRETTE, A.; DEL PRETTE, Z. A. P. Psicologia das relações interpessoais: vivências para o trabalho em grupo. 3. ed. Petrópolis: Vozes, 2017.

FIOROT JR. J. A. Habilidades sociais docentes: avaliação de um programa de formação na perspectiva de professores e alunos. 2020. 88 f. Dissertação (Mestrado) - Universidade de Araraquara, 2020.

FORMOSINHO, J. Ser professor na escola de massas. In: FORMOSINHO, J. (Coord). Formação de professores: aprendizagem profissional e acção docente. Porto, Portugal: Porto, 2009. p. 37-69.

GRESHAM, F. M. Análise do comportamento aplicada às habilidades sociais. In: DEL PRETTE, A.; DEL PRETTE, Z. A. P. Psicologia das relações interpessoais: vivências para o trabalho em grupo. 2. ed. Petrópolis: Editora Vozes, 2013. p.18-23.

HENRIQUE, R. B. Habilidades sociais educativas dos professores dos anos iniciais do ensino fundamental. Orientador: Dagma Venturini Marques Abramides. 2017. $78 \mathrm{f}$. Dissertação (Mestrado em Ciências) - Universidade de São Paulo, Bauru, SP. Disponível em: 
http://www.teses.usp.br/teses/disponiveis/25/25143/tde-16082017-180923/pt-br.php. Acesso em: 1 maio 2020.

IBGE. INSTITUTO BRASILEIRO DE GEOGRAFIA E ESTATÍSTICA. 2018: Educação Tabelas. Rio de Janeiro, 2018. Disponível em:

https://www.ibge.gov.br/estatisticas/sociais/trabalho/17270-pnad-

continua.html?edicao $=24772 \& \mathrm{t}=$ resultados. Acesso em: 7 jun. 2020.

KING, C.; MORRISON, J. Grok: the game. Trad. Laura Claessens e Sérgio Luciano. 2. ed. São José dos Campos: Colab Colibri, 2018.

LIPPI, F. Coaching in a box: 100 perguntas para iniciar um processo de autodesenvolvimento e alta performance com os mais importantes conceitos de coaching. 1 . Ed. São Paulo: Matrix, 2010.

MARTINEZ, J. E.; GRASSI, D. C.; MARQUES, L. G. Análise da aplicabilidade de três instrumentos de avaliação de dor em distintas unidades de atendimento: ambulatório, enfermaria e urgência. Rev. Bras. Reumatol., São Paulo, v. 51, n. 4, p. 304-308, ago. 2011. Disponível em: http://www.scielo.br/scielo.php?script=sci_arttext\&pid=S048250042011000400002\&lng=en\&nrm=iso. Acesso em: 9 maio 2020.

MANOLIO, C. L. Habilidades sociais educativas na interação professor-aluno. 2009. 159 f. Dissertação (Mestrado) - Universidade Federal de São Carlos, São Carlos, SP. Disponível em:

http://repositório.ufscar.br/bitstream/handle/ufscar/3017/2324.pdf?sequence=1\&isAllowed=y. Acesso em: 2 maio 2020.

MINAYO, M. C. S.; SANCHES, O. Quantitativo-qualitativo: oposição ou complementaridade? Cad. Saúde Pública, Rio de Janeiro, v .9, n. 3, p. 237-248, 1993. ISSN 1678-4464. DOI: https://doi.org/10.1590/S0102-311X1993000300002

ROSENBERG, M. B. Comunicação não violenta: técnicas para aprimorar relacionamentos pessoais e profissionais. São Paulo. Ágora, 2006.

SKINNER, B. F. Ciência e comportamento humano. 2. ed. São Paulo: Martins Fontes, 2007.

TEDESCO, J. C. O novo pacto educativo: educação, competitividade e cidadania na sociedade moderna. São Paulo: Ática, 2001.

VILLAS BOAS, A. C. V. B.; SILVEIRA, F. F.; BOLSONI-SILVA, A. T. Descrição de efeitos de um procedimento de intervenção em grupo com universitários: um estudo piloto. Interação em Psicologia, Curitiba, v. 9, n. 2, p. 321-330, 2005. 


\section{Como referenciar este artigo}

FIOROT JUNIOR, J. A.; DRAGONE, M. L. S. Avaliação de um Programa de Formação em Habilidades Sociais Docentes na perspectiva de professores e alunos. Doxa: Rev. Bras. Psico. e Educ., Araraquara, v. 22, n. 2, p. 394-409, jul./dez. 2020. e-ISSN: 2594-8385. DOI: https://doi.org/10.30715/doxa.v22i2.13924

Submetido em: 10/04/2020

Revisões requeridas: $10 / 07 / 2020$

Aprovado em: $15 / 07 / 2020$

Publicado em: 31/08/2020 